\title{
Apakah Perceived Quality memediasi hubungan antara brand Image dan Country of Origin terhadap Purchase Intension?
}

\author{
Kussudyarsana Kussudyarsana, Yessy Bangkit Forma, Nur Achmad \\ Fakultas Ekonomi dan Bisnis, Universitas Muhammadiyah Surakarta, Indonesia
}

This study analyzes the effect of country of origin and brand image on purchnase intension through perceived quality as an intervening variable. The research setting was on Skin cares and Beauty clinic Industry. This research used incidental sampling as a sampling technique. This study involved 300 respondents which acces the online questionnaires through google form. The data obtained were processed used descriptive analysis and SEM analysis with SmartPLS. The results indicate that the country of origin positively effect on perceived quality. Meanwhile, the country of origin variable did not affect on purchase intension. The brand image variable has a positively impact on the perceived quality variable. rand image has a positive effect on intension to buy. The perceived quality positively effects on intension to buy. Ccountry of origin indirectly effect on intension to buy through perceived quality. rand image has an indirect effect on intension to buy through perceived quality as an intervening variable.

Keywords : country of origin, brand image, perceived quality, purchase intension

\section{OPEN ACCESS}

ISSN 2528-4649 (online) ISSN 2338-4409 (print)

Reviewed by:

Asat Rizal \& Qristin Violinda \& Nurul

Qomariah

${ }^{*}$ Correspondence:

Received: 26 Juli 2020 Accepted: 28 Agustus 2020 Published: 30 September 2020

Citation:

Kussudyarsana K, Bangkit Forma Y and Achmad N (2020) Apakah

Perceived Quality memediasi hubungan antara brand Image dan

Country of Origin terhadap

Purchase Intension?

JBMP. 6:2.

doi: 10.21070/jbmp.v6i2.770
Studi ini berupaya untuk menguji dampak country of origin dan brand image pada intensi pembelian pengguna skincare di Surakarta, dengan perceived quality sebagai variabel mediator. Sampel yang diambil berjumlah 300 orang responden, dengan teknik sampling incidental. engumpulan data menggunakan kuesioner online (google form) dengan menyebarkan kuesioner kepada responden yaitu para mahasiswa di perguruan tinggi di Kota Surakarta. Pengolahan data dalam studi ini menggunakan analisis SEM dengan SmartPLS. Hasil studi ini menunjukkan bahwa varia el country of origin berdampak po itif pada varia el perceived quality. Sedangkan Varia el country of origin tidak mempunyai pengaruh pada varia el intensi pembelian. Varia el brand image secara positif mempengaruhi perceived quality. Adapun Variabel perceived mempengaruhi intensi pembelian secara positif. Brand image secara positif berdampak pada intensi pembelian. Hasil studi ini menunjukkan bahwa perceived quality memediasi hubungan antara country of origin dan intensi pembelian, serta antara brand image dan intensi pembelian.

Kata kunci: country of origin, brand image, perceived quality, intensi pembelian, skin care 


\section{INTRODUCTION}

Di Indonesia industri kecantikan mengalami peningkatan dari tahun ke tahun. Data Kementerian Perindustrian memperlihatkan bahwa industri disektor ini tumbuh sebesar 20\%, hampir empat kali pertumbuhan ekonomi nasional (Kemenperin.go.id, 2018). Fenomena tersebut memperlihat bahwa bisnis ini mempunyai prospek yang sangat menjanjikan. Hal ini mendorong banyak perusahaan berlomba-lomba menciptakan differensiasi dan inovasi guna mempertahankan eksistensi mereka di pasar persaingan. Persaingan yang kompetitif tidak hanya dengan pemain lokal saja, melainkan juga pemain asing.

Bagi kaum millenial, kecantikan merupakan asset penting yang harus terpenuhi untuk meningkatkan kepercayaan diri mereka dalam berinteraksi di kehidupan sosial. Penggunaan produk kecantikan bukan lagi untuk memenuhi keinginan (wants) saja, tetapi juga untuk kebutuhan (needs) pada saat ini (Novita, 2019). Seiring dengan meningkatknya kesadaran konsumen akan pentingnya kesehatan, maka mereka tidak lagi melihat kosmetika sebagai alat dekoratif saja, akan tetapi juga alat untuk perawatan kuli(Ghaizani, Pangestuti, \& Devita, 2018).

Beredarnya produk skincare yang ada di kalangan masyarakat baik produk dalam negeri maupun luar negeri, membuat konsumen lebih selektif dalam pemilihan produk mulai dari desain produk, manfaat produk, merek, dan darimana produk skincare itu berasal terutama di kalangan kaum hawa yang cenderung lebih selektif dalam memilih produk skincare sesuai selera dan kecocokan kulit mereka dengan menggali informasi sebanyak-banyaknya mengenai produk skincare yang mereka minati.

Salah satu aspek yang mungkin dipertimbangkan oleh konsumen dalam memilih kosmetik adalah country of origin. Country of origin (COO) dapat dikenali dari tulisan "Made in" yang tertera pada produk tersebut. COO merupakan bagian yang penting dalam perilaku konsumen karena menjadi petunjuk bagi konsumen dalam mengevaluasi suatu produk (Aichner 2017), dan itu sangat penting bagi perilaku pembelian konsumen (Beverland and Lindgreen 2002). Country of origin merupakan faktor yang penting dalam mempengaruhi evaluasi merek, persepsi dan perilaku pembelian. COO dapat memberikan dukungan bagi merek agar menjadi lebih kompetitif di pasaran. Negara dengan citra (image) yang positif dapat mempertinggi penempatan produk (product positioning), mengurangi resiko terkait dengan pembelian produk (Cristea Adina, Capatina Gabriela \& Stonescu Roxana-Denia, 2015). Konsumen menggunakan COO sebagai petunjuk ekstrinsik terutama untuk mengevaluasi produk baru, dibandingkan atribut intrinsik dari suatu produk spesifik (Michaelis et al. 2008).

Faktor lain selain Country of origin dalam pengaruhnya pada intensi pembelian adalah Brand image. Brand image merupakan ukuran kepercayaan yang dipegang konsumen yang berkaitan dengan suatu merek tertentu (Wibisono,
2019). Country of origin dan brand image adalah dua isyarat penting yang mempengaruhi intensi pembelian konsumen melalui persepsi kualitas (Adenan, Ali, Humida, \& Abdul, 2018). Secara umum, konsumen tidak segan untuk mengeluarkan uang lebih banyak untuk membeli suatu produk yang dibuat dari negara dengan citra yang lebih menguntungkan (Koschate-Fischer et al. 2012).

Kebutuhan pasar skincare di Indonesia sangat tinggi, tetapi permintaan yang tinggi tidak mampu diproduksi dalam negeri, sehingga produk luar negeri masuk dan mengambil alih (Winarni, 2019). Berikut adalah daftar enam Top Brand Index berdasarkan survey yang dilakukan ZAP Beauty Index dan Mark Plus Inc pada 17.889 perempuan Indonesia.

Tabel 1 Indonesia Skincare Sales Market Share 2018

\section{[Table 1 about here.]}

Berdasarkan data di atas, brand yang diminati oleh konsumen Indonesia kebanyakan dari negara Korea Selatan, sedangkan brand Wardah yang berasal dari Indonesia menduduki posisi nomor 6 sebagai top brand index di Indonesia. Fenomena di atas mengundang pertanyaan, mengingat kosmetik (skincare) dari luar negeri belum tentu cocok dengan kulit orang Indonesia, namun diminati oleh konsumen Indonesia. Hal apa saja yang mendorong masyarakat Indonesia berminat untuk melakukan pembelian pada kosemetik dari luar negeri. Beberapa kajian sebelumnya telah mencoba menghubungkan perceived quality dengan country of origin dan intensi pembelian (misal Dinata 2017, Kurniasari 2017). Namun kajian tersebut belumlah lengkap, karena belum memasukan unsur brand image sebagai variabel yang mungkin berpengaruh terhadap intensi pembelian. Beberapa kajian memperlihatkan hubungan antara brand image dengan intensi pembelian (Adenan, Ali, Humida, \& Abdul, 2018). Namun demikian, kajian yang menghubungkan brand image dengan country of origin dengan purchase intension belum banyak dilakukan. Berdasarkan fenomena di atas, peneliti tertarik untuk melakukan studi pengaruh Country of Origin dan Brand Image pada Intensi pembelian dengan Perceived Quality sebagai variabel Intervening penggunaan skincare di Indonesia.

\section{TINJAUAN PUSTAKA}

Konsumen yang rasional akan mempertimbangkan informasi yang mereka terima untuk membuat keputusan. Keputusan yang dibuat oleh konsumen pada umumnya didasarkan oleh penilaian mereka atas produk baik itu dari segi kualitas produk ataupun harga. Adanya keterbatasan informasi atas produk membuat konsumen mencari indikasi atas kualitas dari popularitas merek, harga atau indikator lainnya. Country of origin atau negara asal sebuah produk, akan digunakan sebagai standar kualitas suatu produk sebelum konsumen melakukan pembelian (Ardiani, 2019).

Menurut Kotler dan Keller (2006) kepercayaan seseorang pada suatu produk berkaitan dengan dari mana produk 
tersebut di buat. Country of origin digunakan untuk membantu konsumen dalam mengenali brand image suatu produk dimana konsep citra merek payung ditekankan (Adenan, Ali, Humida, \& Abdul, 2018). Informasi ini menjadi penting karena suatu negara mempunyai citra tertentu bagi konsumen global (Munir, Nurhajati, \& Wahono, 2019). Namun demikian tentu saja, perusahaan asal merek dapat berbeda dengan negara asal pembuatnya. Bisa jadi produk dari merek yang indentik dengan negara tertentu dibuat di negara lain.

Studi sebelumnya mengindikasikan bahwa terdapat hubungan antara country of origin perceived quality dan intensi pembelian. Suatu negara tertentu dikenal di pasar global sebagai penghasil produk tertentu, dengan kualitas tertentu. Studi Dinata (2015) menunjukkan bahwa Country of Origin memiliki pengaruh signifikan pada persepsi kualitas. Country of Origin juga dapat menjadi sebuah prediktor dalam proses pembelian apabila konsumen mendapat kesulitan dalam hal mengevaluasi kualitas produk dan spesifikasinya. Seperti yang dikatakan Magnusson dan Westjohn (2011) dalam studinya yang menyebutkan bahwa konsumen menghadapi berbagai kesulitan yang melekat pada suatu produk dalam mendapatkan akses informasi intrinsik sebelum pembelian, yang berarti bahwa konsumen sering dipaksa untuk bergantung pada isyarat ekstrinsik seperti merek, harga, dan outlet ritel yang bersangkutan ketika membentuk sebuah penilaian produk. Konsumen akan menghubungkan antrara kualitas produk tertentu dengan negara pembuatnya. Berdasarkan uraian di atas, dapat dibuat hipotesis sebagai berikut.

\section{$\mathrm{H}_{1}$ : Country of origin berdampak positif pada perceived quality}

Petunjuk asal merek (Country of Origin) diduga tidak saja berhubungan dengan persepsi kualitas, akan tetap juga dengan intensi pembelian. Intensi pembelian adalah suatu dorongan yang memotivasi seseorang untuk melakukan pembelian karena adanya perasaan seseorang terhadap suatu produk (Kotler 2000). Seseorang yang mengetahui informasi asal suatu produk dapat saja menjadi tertarik untuk melakukan pembelian. Studi Kurniasari (2017) menunjukkan bahwa country of origin berdampak secara signifikan pada purchase intension.

\section{$\mathrm{H}_{2}$ : Country of origin berdampak positif pada intensi pembelian.}

Citra merek ( rand image) merupakan gambaran konsumen atas suatu merek tertentu sebagai dampak dari komunikasi pemasaran yang dilakukan oleh perusahaan. Untuk dapat mengenalkan, meningkatkan citra dan membangun merek, pemasar melakukan branding (Faraditta, 2015). Selain itu, citra ini juga terbentuk sebagai hasil dari evaluasi konsumen atas pengalaman yang mereka peroleh ketika mereka menggunakan dan mengkonsumsi merek tertentu. Hasil kajian dari Suraputra dan Suardana (2019) memperlihatkan bahwa merek terbukti berdampak positif dan signifikan pada persepsi kualitas.

\section{$\mathrm{H}_{3}:$ Brand image berdampak positif pada perceived quality.}

Perceived quality merupakan penilaian konsumen atas kualitas suatu produk. (Tutia \& Najib, 2019). Pada umumnya konsumen akan menghubungkannya dengan pengalaman dan informasi yang mereka dapatkan atas suatu merek. Merek mempunyai citra yang diasosiasikan dengan kualitas tertentu. Perceived quality bersifat subyektif karena konsumen menilai suatu produk berdasarkan apa yang mereka ketahui saat itu. Karena merek adalah identitas suatu produk, maka dengan sendiri konsumen akan menilai suatu produk berdasarkan citra merek yang melekat pada produk tersebut. Dalam kaitannya dengan niat beli, citra merek dapat berpengaruh langsung ataupun tidak langsung. Kajian dari Suraputra dan Suardana (2019) mengindikasikan bahwa merek, desain, dan harga secara langsung dan tidak langsung berdampak niat beli. Merek melalui mediasi persepsi kualitas berdampak positif dan signifikan pada niat beli.

\section{$\mathrm{H}_{4}:$ Brand image berdampak positif pada intensi pembelian.}

Seorang konsumen akan mempertimbangkan tingkat kualitas tertentu dari suatu produk sebelum melakukan pembelian. Apabila konsumen merasa bahwa produk yang mereka lihat masih dalam area kualitas yang bisa diterima, konsumen berminat untuk melakukan pembelian. Sebaliknya, apabila kualitas dari produk yang mereka jumpai berada diluar area pertimbangan, kecil kemungkinan konsumen akan melakukan pembelian pada produk tersebut. Kajian dari Efendi, Rachma, dan Rahmat (2019) memperlihatkan bahwa country of origin perception, perceived quality, dan price memiliki pengaruh langsung pada intensi pembelian.

\section{$\mathrm{H}_{5}:$ Perceived quality memiliki pengaruh positif pada intensi pembelian.}

Kotler dan Keller (2008), menunjukkan bahwa konsumen akan mengevaluasi berbagai hal yang berkenaan dengan produk sebelum membuat keputusan pembelian. Kotler dan Keller (2009) berpendapat bahwa kepercayaan konsumen pada suatu produk dapat muncul dikarenakan adanya identitas negara di mana produk tersebut di buat. Namun demikian, kami menduga bahwa informasi tentang asal negara tersebut tidak serta merta mempengaruhi minat pembelian. Kajian dari Rahmawansyah (2019) memperlihatkan bahwa COO (country of origin) tidak berdampak secara langsung pada intensi pembelian, Studi yang dilakukan Rahmawansyah, (2019) menunjukkan adanya pengaruh positif yang signifikan dari country of origin pada intensi pembelian yang dimediasi oleh variabel 
perceived quality.

\section{$\mathrm{H}_{6}$ : Country of origin berdampak tidak langsung pada intensi pembelian melalui perceived quality sebagai variabel intervening.}

Merek dapat diartikan sebagai nama, simbol, desain atau kombinasi dari suatu produk yang bertujuan untuk memudahkan dentifikasi barang dan jasa dan untuk membedakan mereka dari pesaing (Kotler \& Keller, 2009). Hasil kajian beberapa peneliti sebelumnya menunjukkan adanya perbedaan sudut pandang tentang hubungan antara citra merek (brand image) pada intensi pembelian. Sebagian berpendapat bahwa citra merek berdampak langsung pada. Sebagian yang lain berpendapat bahwa citra merek mempengaruhi intensi pembelian melalui perceived quality. Suraputra dan Suardana, (2019) memandang bahwa citra merek dapat mempengaruhi minat pembelian. Beberapa peneliti lain berpendapat bahwa citra merek menjadi mediator bagi percieved quality dan COO pada intensi pembelian. Studi yang dilakukan Efendi, Rachma, dan Rahmat (2019) dengan menggunakan analisis jalur menunjukkan bahwa Country of Origin (COO) Perception, Perceived Quality, dan Price memiliki pengaruh tidak langsung pada Intensi pembelian, melalui Brand image. Dalam studi ini, peneliti menduga bahwa citra merek tidak secara langsung berdampak pada intensi pembelian, namun melalui perceived quality.

\section{$H_{7}:$ Brand image berdampak tidak langsung pada intensi pembelian melalui perceived quality sebagai variabel intervening. Kerangka Pemikiran}

[Figure 1 about here.]

\section{METODE PENELITIAN}

Studi ini menggunakan sumber data primer untuk membuktikan menjawab pertanyaan penelitian. Sumber data berasal dari 300 responden mahasiswa pengguna skincare di perguruan tinggi di Surakarta. Untuk mengumpulkan data, peneliti menggunakan google form yang berisikan daftar pertanyaan yang dikembangkan dari kuesioner yang telah digunakan sebelumnya. Penyebaran dilakukan secara langsung kepada responden yaitu para mahasiswa di perguruan tinggi di Surakarta yang ditemui dan kuisioner diberikan secara langsung fakultas Ekonomi dan Bisnis.

Pengolahan data studi menggunakan analisis deskriptif dan analisis Structural Equation Modeling (SEM) dengan SmartPLS 3.0. Studi ini, analisis deskriptif digunakan untuk menganalisis gambaran karakteristik konsumen pengguna skincare. SEM adalah suatu jenis teknik analisis Multivariat yang dapat menguji model yang komplek dimana dalam model tersebut terdapat banyak hubungan langsung dan tidak langsung dengan cara simultan. Analisis SEM PLS dalam studi ini digunakan untuk menganalisis pengaruh langsung antar country of origin, brand image, dan perceived quality pada intensi pembelian.

\section{HASIL PEMBAHASAN}

\section{Diskripsi Data}

Responden dalam penelitian ini dapat di diskripsikan menurut usia, latar belakang studi dan merek produk skin care yang dipilih. Usia merupakan batasan umur responden yang diteliti. Berdasarkan usia mereka responden, terbagi ke dalam 2 golongan besar, yaitu antara 19-23 tahun dan antara 2427 tahun. Adapun keadaan usia responden dapat dilihat pada tabel berikut:

\section{[Table 2 about here.]}

Berdasarkan tabel diketahui responden sebagian besar berusia antara usia 19-23 tahun sebanyak 157 orang atau 52,33\%, mahasiswa dengan usia 24-27 tahun sebanyak 143 orang atau $47,67 \%$

[Table 3 about here.]

Berdasarkan tabel 3 diketahui responden yang menggunakan merek produk skincare SK II sebanyak 26 orang (26\%), Laneige sebanyak 41 orang (13,7\%), Body Shop sebanyak 43 orang $(14,3 \%)$, Innisfree sebanyak 37 orang (12,3\%), Nature Republic sebanyak 63 orang (21\%), Wardah sebanyak 78 orang $(26 \%)$, dan lainnya sebanyak 12 orang $(4 \%)$.

\section{Analisis Data}

Uji validitas dan reliabilitas dilakukan terhadap instrumen penelitian untuk mendapatkan instrumen yang valid dan reliabel. Uji validitas dilakukan melalui pengujian convergent dan discriminant validity. Adapun pengujian reliabilitas dilakukan dengan melihat nilai omposite reliability dan cronbach alphanya.

\section{a. Skema Model Partial Least Square}

Skema model dalam studi ini dapat di lihat pada gambar 2. Dalam skema ini tergambar hubungan yang bersifat reflektif dan formatif, yang menggambarkan hubungan antara variabel laten dan indikatornya, serta diantara variabel laten itu sendiri. Melalui skema ini, dilakukan pengujian outer model dan inner model.

[Figure 2 about here.]

[Figure 3 about here.] 


\section{b. Evaluasi Outer Model}

Model outer akhir dari studi ini menghasilkan variabel country of origin yang direfleksikan oleh 4 indikator, variabel brand image direfleksikan oleh 5 indikator, variabel perceived quality direfleksikan oleh 6 indikator, dan variabel intensi pembelian direfleksikan oleh 4 indikator.

Model outer pada intinya adalah menguji model reflektif, yaitu hubungan causalitas antara variabel laten dengan indikatornya. Karena indikator adalah cerminan dari variabel latennya, maka, seharusnya keduanya mempunyai hubungan yang kuat satu sama lain.

Hasil pengujian adalah sebagai berikut:

\section{1) Convergent Validity}

Berdasarkan hasil analisis, diketahui bahwa sebagain besar yang memiliki outer loading sebesar $>0,7$. Suatu instrumen dianggap valid apabila indikator mempunyai outer loading di atas $>0$,7. Menurut Ghozali (2006) untuk studi tahap awal dari pengembangan skala pengukuran nilai loading 0,5 sampai 0,6 dianggap cukup memadai. Dalam studi ini tidak ada nilai outer loading yang kurang dari 0,5 .

\section{2) Discriminant Validity}

Discriminant Validity dapat dilihat dengan membandingkan skor Average Variant Extracted (AVE) dibandingkan dengan rule of thumb-nya. Dengan metode ini suatu instrumen di anggap valid apabila mempunyai skor AVE sebesar $>0,5$. Skor AVE dari variabel country of origin sebesar 0,646 atau $>0,5$. Adapun untuk nilai variabel brand image sebesar 0,513 atau > 0,5 . Untuk nilai variabel perceived quality 0,542, sehingga AVE $>0,5$ dan sebesar 0,563 dan untuk variabel intensi pembelian atau AVE $>0,5$.

\section{3) Composite Reliability}

Suatu indikator di katakan reliabel dengan kriteria composite reliability apabila mempunyai skor $>0,7$. Variabel country of origin sebesar 0,877 , brand image yaitu 0,838 , perceived quality $(0,876)$, dan intensi pembelian sebesar 0,836 . Hasil ini menunjukkan bahwa keempat variabel tersebut reliabel.

\section{4) Cronbach's Alpha}

Untuk mendukung pengujian reliabilitas, dilakukan pengujian melalui Cronbach's Alpha. Berdasarkan hasil dari Cronbach's Alpha variabel country of origin yaitu sebesar 0,811 , brand image sebesar 0,758 , perceived quality sebesar 0,830 , dan intensi pembelian sebesar 0,737. Hal ini menunjukkan bahwa skornya di atas $>0,70$. Berdasarkan hasil tersebut dapat di simpulkan bahwa instrumen tersebut mempunyai reliabilitas yang tinggi.

\section{Uji Multikolinearitas}

Uji multikolinieritas digunakan untuk memastikan bahwa diantara variabel bebas tidak terdapat korelasi yang tinggi satu sama lain. Berdasarkan hasil dari Collinierity Statistics (VIF) untuk melihat uji multicolinierity dengan hasil nilai inner dari variabel country of origin sebesar pada intensi pembelian sebesar 1,519 dan pada perceived quality sebesar 1,348. Kemudian nilai dari variabel brand image sebesar 1,605 dan pada perceived quality sebesar 1,348. Nilai dari variabel perceived quality pada intensi pembelian sebesar 1,641. Dari masing-masing variabel VIF $<10$ maka tidak melanggar uji asumsi multikolineraritas.

\section{Uji Koefisien jalur}

Hasil pengujian inner model di gambar 2 memperlihatkan bahwa seberapa besar pengaruh dari masing-masing variabel bebas terhadap variable terikatnya. Koefisien jalur tebesar ditunjukkan dari pengaruh country of origin pada perceived quality sebesar 6,912. Diikutnya dengan pengaruh brand image pada perceived quality sebesar 6,670. Selanjutnya pengaruh brand image pada intensi pembelian sebesar 5,367. Pengaruh perceived quality pada intensi pembelian sebesar 2,922. Terakhir, pengaruh country of origin pada intensi pembelian sebesar 0,241 .

\section{Uji Goodness of Fit}

Tabel $R$-Square memperlihatkan pengaruh variabel country of origin dan brand image pada perceived quality serta besarnya pengaruh variabel country of origin, brand image dan perceived quality pada variabel intensi pembelian. Berdasarkan hasil analisis, dapat diketahui bahwa besar pengaruh country of origin, brand image pada perceived qualty sebesar 0,391 atau 39, $1 \%$. Adapun pengaruh country of origin, brand image, dan perceived quality pada intensi pembelian ebesar 0,356 atau 35,6\%.

\section{Pengujian Hipotesis}

Uji hipotesis dilakukan dengan membandingkan nilai $t$ statistik hitung dengan $t$ tabel, atau dengan melihat skor $p$ valuesnya. Apabila $P$ values $<0,05$, maka hipotesis alternatif di terima dan hipotesis nol di tolak. Studi ini juga berupaya untuk menguji pengaruh langsung dan pengaruh tidak langsung:

\section{Pengujian Pengaruh Langsung}

Studi ini berupaya untuk menguji 7 hipotesis. Pengujian hipotesis menggunakan teknik analisis bootstraping. Melalui nilai t-statistik yang diperoleh dapat diketahui ignifikansi pengaruh variabel independen terhadap variabel dependen. Apabila nilai t-statistik $>1,967$ (t-tabel signifikansi 5\%) dan nilai $P$ Value pada setiap variabel $<0,05$, maka $\mathrm{H}_{0}$ ditolak. Pegaruh positif dapat dilihat melalui Original Sample.

Dari hasil pengujian, diketahui nilai t-statistik pengaruh variabel country of origin terhadap perceived quality sebesar 6,912 atau lebih besar dari $\mathrm{t}$ tabel $(1,967)$ dan nilai $P$ Values $<0.05$ sebesar 0,000. Ini berarti bahwa $\mathbf{H}_{1}$ yaitu country of origin berdampak positif pada perceived quality diterima.

[Table 4 about here.] 
Nilai t statistik dari pengaruh country of origin pada intensi pembelian lebih kecil dari t tabel $(1,967)$ yaitu sebesar 0,241 dengan besar pengaruh 0,016 dan $P$ Values $>0,05$ sebesar 0,810. Sehingga dapat disimpulkan pengaruh dari country of origin pada intensi pembelian adalah positif dan tidak signifikan. Maka tidak sesuai dengan $\mathbf{H}_{2}$ : Country of origin berdampak positif pada intensi pembelian, dengan demikian $\mathrm{H}_{2}$ ditolak.

Nilai t statistik dari pengaruh brand image pada perceived quality lebih besar dari nilai t tabel $(1,967)$ yaitu sebesar 6,670 dengan besar pengaruh 0,395 dan $P$ Values $<0,05$ sebesar 0,000 . Sehingga dapat disimpulkan pengaruh brand image pada perceived quality adalah positif dan signifikan. Maka $\mathbf{H}_{3}$ : Brand image berdampak positif pada perceived quality diterima.

Nilai t statistik dari pengaruh brand image terhadap intensi pembelian sebesar 5,367 atau $\mathrm{t}$ hitung $>\mathrm{t}$ tabel $(1,967)$ dan $P$ Values sebesar 0,000 , atau $<0,05$ dengan nilai pengaruhnya sebesar 0,427 . Berdasarkan hasil tersebut, dapat disimpulkan bahwa brand image berpengaruh secara positif dan signifikan terhadap intensi pembelian. Dengan demikian hipotesis 4 diterima.

Selanjutnya, studi ini juga menemukan bahwa perceived quality berpengaruh secara positif dan signifikan. Hal ini bisa terlihat dari Nilai $t$ statistik sebesar 2,922 atau lebih besar dari $\mathrm{t}$ tabel $(1,967)$, dan $P$ Values $<0,05$ sebesar 0,004 .

\section{Pengujian Pengaruh Tidak Langsung}

Pengujian indirect effect digunakan untuk membuktikan pengaruh tidak langsung variabel country of origin pada intensi pembelian dan pengaruh tidak langsung brand image pada intensi pembelian. Kedua variabel tersebut di duga mempengaruhi intensi pembelian melalui perceived quality. Tabel 3 memperlihatkan bahwa nilai t statistik pengaruh country of origin terhadap intensi pembelian melalui perceived quality adalah sebesar 2,723 atau lebih besar dari t tabel $(1,967)$, dengan besar pengaruh 0,074 dan $P$ Values $<0,05$ sebesar 0,007. Sehingga dapat disimpulkan bahwa country of origin berpengaruh pada intensi pembelian melalui perceived quality adalah positif dan signifikan. Berdasarkan hasil tersebut, maka $\mathrm{H}_{6}$ diterima.

[Table 5 about here.]

Nilai $t$ statistik pengaruh brand image pada intensi pembelian melalui perceived quality adalah sebesar 2,555 atau lebih besar dari t tabel $(1,967)$ dengan besar pengaruh 0,091 dan $P$ Values $<0,05$ sebesar 0,011 . Sehingga dapat disimpulkan bahwa brand image berpengaruh terhadap intensi pembelian melalui perceived quality adalah positif dan signifikan. Berdasarkan hasil tersebut, maka $\mathrm{H}_{7}$ di terima.

\section{Pengaruh Total Hubungan antara Country of Origin dan Intensi pembelian dengan Perceived Quality sebagai Variabel Intervening}

Pengujian pengaruh total digunakan untuk menguji apakah hubungan yang terjadi bersifat fully mediation atau partial mediation. Fully mediation terjadi apabila variabel bebas hanya bisa menjelaskan variabel terikat melalui variabel intervening. Ini artinya pengaruh tidak langsungnya signifikan, tetapi pengaruh langsungnya tidak signifikan. Sebaliknya Partial Mediation terjadi jika pengaruh langsung dan tidak langsung adalah signifikan (Rahmawansyah, 2019). Dalam studi ini ,nilai tstatistik hitung variabel country of origin pada perceived quality adalah sebesar 6,912 dan nilai t- statistik hitung pengaruh perceived quality terhadap intensi pembelian sebesar 2,922, atau lebih besar dari $\mathrm{t}$ tabel. $(1,967))$. Sedangkan pengaruh langsung variabel country of origin pada intensi pembelian tidak signifikan dengan nilai t-hitung $<\mathrm{t}$ tabel $(0,241<(1,967)$. Hasil pengujian tersebut memperlihatkan hubungan mediasi penuh (fully mediation).

\section{[Table 6 about here.]}

Untuk lebih jelasnya dalam mengetahui pengaruh total antara country of origin dan intensi pembelian dengan perceived quality sebagai variabel intervening disajikan pada gambar sebagai berikut:

[Figure 4 about here.]

Gambar 4 memperlihatkan model mediasi penuh (full mediation) country of origin terhadap intensi pembelian. Pertama, country of origin secara signifikan mempengaruhi perceived quality. Hal ini terlihat dari nilai t-statistik sebesar 6,912 yang berarti lebih besar dari nilai t-tabel $(1,967)$. Kedua, perceived quality secara langsung mempengaruhi intensi pembelian (t-hitung 2,922>t-tabel 1,96). Ketiga country of origin tidak mempengaruhi intensi pembelian $(0,41<1.96)$.

\section{Pengaruh Total Hubungan antara Brand Image dan Minat Beli dengan Perceived Quality sebagai Variabel Intervening}

Tabel 6 dan gambar 5 memperlihatkan uji statistik penngaruh total dari brand image (BI) terhadap intensi pembelian (PI) melalui perceived quality (PQ). Hasil pengujian memperlihatkan bahwa brand image secara signifikan mempengaruhi perceived quality $(, 670>1,96)$ dan perceived quality secara signifikan pula mempengaruhi intensi pembelian $(2,992>1,96)$. Demikian juga dengan brand image terhadap intensi pembelian (PI) $(5,367>1,96)$. Secara total brand image secara signifikan mempengaruhi intensi pembelian (BI-PQ-PI) yang terlihat dari nilai thitung $(2,723)$ lebih besar dari t tabel $(1,96)$.

Tabel 6

Pengaruh Total Hubungan antara Brand Image dan Minat Beli dengan Perceived Quality sebagai Variabel Intervening

[Table 7 about here.]

Berdasarkan pengujian ini, maka dapat disimpulkan bahwa model yang terbentuk dari pengaruh brand image terhadap intensi pembelian melalui percieved quality adalah model partial mediation. Hal ini terlihat dari pengaruh langsung dan 
tidak langsung brand image terhadap intensi pembelian adalah signifikan.

[Figure 5 about here.]

\section{PEMBAHASAN}

Hasil studi ini membahas tentang hasil analisis pengaruh country of origin, brand image pada intensi pembelian dengan perceived quality sebagai variabel intervening dan studi pada pengguna skincare diperguruan tinggi di Surakarta. Berdasarkan karakteristik responden, menurut klasifikasi usia diketahui responden sebagian besar berusia antara usia 1923 tahun sebanyak 157 orang atau 52,33\%, mahasiswa dengan usia $24-27$ tahun sebanyak 143 orang atau $47,67 \%$ dengan jenis kelamin wanita. Berdasarkan klasifikasi fakultas diketahui responden sebagian besar merupakan fakultas Ekonomi dan Bisnis sebanyak 160 orang (53,22\%), fakultas Hukum sebanyak 60 orang (20\%) dan fakultas FKIP sebanyak 80 orang (26,67\%).

Berdasarkan merek skincare diketahui responden yang menggunakan merek produk skincare SK II sebanyak 26 orang (26\%), Laneige sebanyak 41 orang (13,7\%), Body Shop sebanyak 43 orang $(14,3 \%)$, Innisfree sebanyak 37 orang $(12,3 \%)$, Nature Republic sebanyak 63 orang $(21 \%)$, Wardah sebanyak 78 orang (26\%), dan lainnya sebanyak 12 orang (4\%).

Hasil dari studi ini berdasarkan pengujian hipotesis, hasil analisis adalah sebagai berikut:

\section{Pengaruh country of origin pada perceived quality.}

Hasil studi menunjukkan bahwa country of origin memiliki pengaruh positif terhadap perceived quality $(6,912>1,967)$. Hal ini sejalan dengan studi yang dilakukan oleh Dinata (2015), Ardiani (2019), Efendi, Rachma, dan Rahmat (2019), dan Rahmawansyah (2019). Ini berarti bahwa indentitas negara asal suatu produk akan memberikan kesan kualitas yang positif pada produk tersebut. Konsumen percaya bahwa identitas negara asal suatu produk merupakan suatu indikator yang dapat mewakili suatu kualitas tertentu. Ini menjawab keraguan dari perdebatan sebelumnya bahwa informasi negara asal produk tidak lagi dapat mewakili suatu kesan kualitas tertentu.

\section{Pengaruh country of origin pada intensi pembelian}

Kajian ini memperlihatkan bahwa country of origin tidak berpengaruh terhadap intensi pembelian $(0,242$ atau $<1,967)$. Temuan ini sejalan dengan studi yang dilakukan oleh Herdian (2016) yang berpendapat bahwa country of origin tidak berdampak signifikan pada intensi pembelian. Di era teknologi seperti saat ini informasi apapun sangat mudah untuk didapatkan. Banyak faktor yang mendasari pemilihan akan pro- duk skincare seperti harga, iklan yang menarik, citra merek, sehingga konsumen bersikap proaktif dalam menggali informasi dari produk yang mereka ingin beli. Hal inilah yang membuat faktor negara asal atau country of origin suatu produk tidak lagi mempunyai pengaruh yang kuat pada intensi pembelian konsumen. Hasil penelitian ini berbeda dengan temuan Dinata, (2015), dan Kurniasari (2017) yang memperlihatkan country of origin berdampak positif dan signifikan pada intensi pembelian. Perbedaan hasil ini dapat menjadi acuan untuk studi yang selanjutnya. Hal ini berarti bahwa konsumen tidak lagi mendasarkan country of origin sebagai informasi yang penting yang dapat menarik minat konsumen untuk melakukan pembelian. Konsumen lebih mempertimbangkan spesifikasi produk dan pengalaman orang lain dalam menggunakan produk tersebut. Hal ini bisa di pahami, mengingat suatu merek global dapat diproduksi dimana saja, tidak lagi harus di buat di negara di mana merek tersebut berasal. Sehingga hubungan antara persepsi merek dan asal produk menjadi semakin kabur.

\section{Pengaruh brand image pada perceived quality}

Hasil uji hipotesis menunjukkan bahwa brand image berdampak positif pada perceived quality. Berdasarkan hasil analisis menghasilkan nilai t statistik sebesar 6,670 atau >1,967 maka pengaruhnya signifikan dan nlai $P$ Value sebesar 0,000 atau $<0,05$ yang berarti ada pengaruh positif brand image pada perceived quality. Sesuai studi yang dilakukan Tutia dan Najib (2019), Suraputra dan Suardana (2019) yang berpendapat bahwa merek melalui mediasi persepsi kualitas berdampak positif dan signifikan pada niat beli. Pengaruh perceived quality pada intensi pembelian. Hal ini memiliki makna semakin tinggi dan kuat citra merek suatu produk, maka akan menciptakan persepsi kualitas yang positif pula pada produk tersebut.

\section{Pengaruh brand image pada intensi pembelian pada pengguna skincare}

Hasil uji hipotesis menunjukan brand image berdampak positif pada intensi pembelian dengan nilai $t$ statistik sebesar 5,367 atau $>1,967$. Ini berarti bahwa brand image dapat menjadi dorongan bagi konsumen untuk melakukan pembelian. Temuan ini sejalan dengan studi Hanna (2019), Suraputra dan Suardana (2019) yang menunjukkan bahwa citra merek memiliki pengaruh positif dan signifikan terhadap intensi pembelian. Temuan ini mengkonfirmasi pernyataan bahwa semakin tinggi citra merek di mata konsumen, semakin tinggi intensi pembelian konsumen terhadap merek tersebut. 


\section{Pengaruh perceived quality pada intensi pembelian}

Studi ini memperlihatkan bahwa perceived quality berdampak positif pada intensi pembelian $(2,922>1,967)$. Temuan ini sesuai dengan studi dari Rahmawansyah, (2019), Suraputra dan Suardana (2019), Efendi et al., (2019). Ini berarti bahwa semakin tinggi persepsi kualitas suatu produk di mata konsumen, maka semakin tinggi pula intensi pembelian konsumen pada produk tersebut.

\section{Pengaruh country of origin pada intensi pembelian melalui perceived quality sebagai variabel intervening}

Temuan ini menunjukkan bahwa country of origin berdampak positif pada intensi pembelian melalui perceived quality sebagai variabel intervening $(2,723>1,967)$. Studi ini sejalan dengan Rahmawansyah, (2019) yang memperlihatkan bahwa variabel country of origin berdampak positif dan signifikan pada intensi pembelian yang dimediasi oleh variabel perceived quality. Ini berarti bahwa informasi tentang asal negara suatu produk tidak serta merta mendorong konsumen untuk melakukan pembelian suatu produk, namun harus didahului dengan tingkat penerimaan mereka atas kualitas produk yang bersangkutan. Ini bisa dimengerti karena tidak setiap negara mempunyai reputasi kualitas yang baik.

\section{Pengaruh brand image pada intensi pembelian melalui perceived quality sebagai variabel intervening pengguna skincare}

Hasil studi menunjukkan bahwa brand image berdampak positif pada intensi pembelian melalui perceived quality sebagai variabel intervening $(2,555$ atau $>1,967)$. Hasil kajian ini sesuai dengan studi dari Suraputra dan Suardana (2019) dimana citra merek berdampak positif dan signifikan pada intensi pembelian melalui persepsi kualitas sebagai variabel mediasi.Secara keseluruhan, model yang terbentuk adalah mediasi parsial (partial mediation), dimana efek langsung dan efek tidak langsungnya adalah signifikan. Citra merek secara signifikan berpengaruh pada intensi pembelian melalui perceived quality dan secara langsung berpengaruh pada intensi pembelian.

\section{PENUTUP}

Studi ini menguji perceived quality sebagai intervening variabel dari dua model yang berbeda. Model pertama menghasilkan mediasi penuh, dimana percevied quality memediasi hubungan antara country of origin dan intensi pembelian secara penuh. Ini terlihat dari nilai statistik indirect effect yang significant, namun direct effectnya, tidak signifikan. Adapun model kedua adalah model mediasi parsial dimana brand image berpengaruh terhadap intensi pembelian melalui percevied quality yang juga disertai pengaruh langsung brand image ke intensi pembelian yang signifikan pula. Dalam hal pengaruh langsung, varia el country of origin tidak brdampak langsung pada varia el intensi pembelian. Adapun dengan brand image berpengarung langsung pada intensi pembelian. Ini menujukkan bahwa brand image mempunyai pengaruh yang lewat kuat terhadap intensi pembelian dibandingkan country of origin.

\section{UCAPAN TERIMA KASIH}

Saya ucapkan terima kasih kepada semua pihak yang telah mendukung terselesaikannya paper ini. Termasuk dalam hal ini adalah pihak Dekanat FEB UMS, yang telah menyediakan dana penelitian kolaborasi. Ucapan terima kasih juga saya sampaikan kepada Lestari Rejeki dan asisten Lab yang telah membantu pengumpulan data di lapangan.

\section{DAFTAR PUSTAKA}

Adenan, M. A., Ali, J. K., Humida, D., \& Abdul, A. (2018). Country Of Origin, Brand Image and High Involvement Product Towards Customer Intensi pembelian : Empirical Evidence Of Eeast Malaysian Consumer. 20(1), 63-72. https://doi.org/10.9744/jmk.20.1.6 3

Adina, C., Gabriela, C., and Denia, S.,R., 2015, Country of Origin Effects on Perceived Branf Positioning. Procedia Economic and Financ2, 23, 422-427.

Akdeniz Ar, A. (2014). Muncul Negara Pasar Konsumen dari Gambar roduksi , Kepercayaan dan Kualitas Persepsi Merek Global yang Dibuat di Cina.

Aichner, Thomas (2015).Country of Origin marketing: A list of typical strategies with examples, Journal of Brand Management, Vol. 21, I, 81-89.

Ardiani, M. (2019). Analisi Pengaruh Country Of Origin pada Intensi pembelian dengan Citra Merek Sebagai Variabel Intervening ( Studi Pada Konsumen Produk Bedak Wajah Merek Maybelline di Semarang ).

Dinata, J. S. (2015). Country Of Origin dan pengaruhnya pada Persepsi kualitas dan Intensi pembelian ( Survei pada Calon Konsumen yang Berminat Membeli iPad di Indonesia ). 25(1), 1-8.

Efendi, Mf., Rachma, N., \& Rahmat, A. (2019). Pengaruh Country Of Origin, Perceived Quality dan Price pada Intensi pem- 
belian dengan Brand Image Sebagai Variabel Intervening (Studi kasus pada pengguna Oli Castrol di Bengkel Castrol Active Sawojajar Kota Malang). 41-55.

Fitriyah, R., \& Iriani, S. (2014). Pengaruh Negara Asal Pada Persepsi Kualitas. 2.

Ghaizani, A., Pangestuti, E., \& Devita, L. (2018). Pengaruh Country of Origin Pada Brand Image dan Dampaknya Bagi Keputusan Pembelian (Survei Online Pada Konsumen Skincare Etude House di Indonesia). 58(2).

Hanna, F. (2019). Pengaruh Negara Asal dan Citra Merek pada Kualitas Persepsi dan Minat untuk Beli (Studi Produk Politron). 3(April), 284-292.

Herdian, E. (2016). Pengaruh Marketing Mix dan Country of Origin Pada Intensi pembelian Produk Smartphone (Studi Kasus pada Produk Samsung).

Koschate-Fischer, N., Diamantopoulos, A. and Oldenkotte, K. (2012) Are consumers really willing to pay more for a favorable country image? A study of country-of-origin effects on willingness to pay. Journal of International Marketing 20(1): 19-41.

Kurniasari, I. (2017). Pengaruh Country Image dan Beauty Vlogger Review pada Intensi pembelian Konsumen Kosmetik Korea (Studi Kasus pada Althea.kr).

Michaelis, M., Woisetschlager, D.M., Backhaus, C. \& Ahlert, D. (2008). The effects of country of origin and corporate reputation on initial trust - An experimental evaluation of the perception of Polish consumers. International Marketing Review, 25(4), 404-422.

Novita, E. (2019). Pengaruh Country of Origin, Brand Image dan Beauty Vlogger Sebagai Celebrity Endorser Pada Intensi pembelian Lipcream Wardah . ( Studi Kasus pada Mahasiswi Fakultas Ekonomi dan Bisnis Universitas Sumatera Utara ).

Rahmawansyah, I. M. (2019). Pengaruh Country Of Origin Pada Intensi pembelian Produk Uniqlo Yang Dimediasi Oleh Variabel Perceived Quality ( Studi Pada Mahasiswa S1 Universitas Brawijaya Kota Malang ). 1-15.

Suraputra, I. made, \& Suardana, I. B. (2019). Persepsi Kualitas Sebagai Mediator Antara Merek, Desain, Harga dan Niat Beli Sepeda Motor. (1), 138-152.

Tutia, I., \& Najib, M. F. (2019). Pengaruh Citra Merek dan Kesadaran Merek Pada Intensi pembelian Sport Hijab. 697-705.

Wibisono, P. (2019). Pengaruh Persepsi Harga, Citra Merek, Persepsi Kualitas, dan Persepsi Nilai pada Intensi pembelian Konsumen.

Winarni, E. (2019). Country Of origin pada Intensi pembelian pada Smartphone Samsung ( Studi Pada Pengguna Smartphone Samsung di Kota Semarang ).

Yuteva, S. (2010). Analisis Pengaruh Etika Kerja Islam Pada Komitmen Profesi Internal Auditor, Komitmen Organisasi , Dan ( Studi Empiris Pada Internal Auditor Perbankan Syariah. 1-11

Conflict of Interest Statement: The authors declare that the research was conducted in the absence of any commercial or financial relationships that could be construed as a potential conflict of interest.

Copyright $\odot 2020$ Kussudyarsana, Bangkit Forma and Achmad. This is an open-access article distributed under the terms of the Creative Commons Attribution License (CC $B Y$ ). The use, distribution or reproduction in other forums is permitted, provided the original author(s) and the copyright owner(s) are credited and that the original publication in this journal is cited, in accordance with accepted academic practice. No use, distribution or reproduction is permitted which does not comply with these terms. 


\section{LIST OF FIGURES}

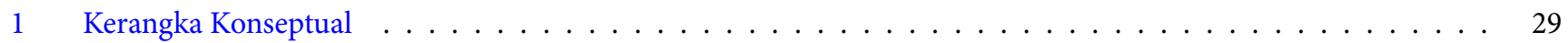

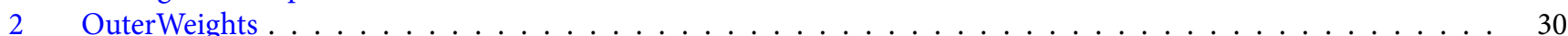

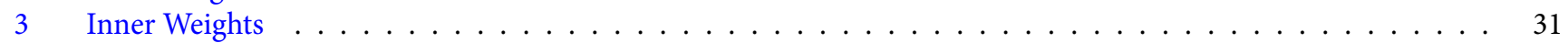

4 Pengaruh Total Hubungan Countryof Origin terhadap Intensi pembelian dengan Perceived Quality sebagai vari-

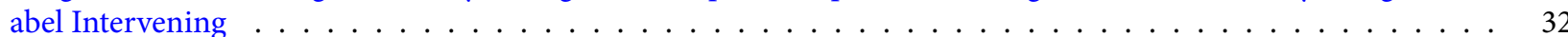

5 Pengaruh Total Hubungan BrandImage terhadap Intensipembelian dengan Perceived Qualitysebagai variabel

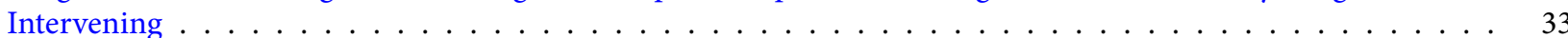




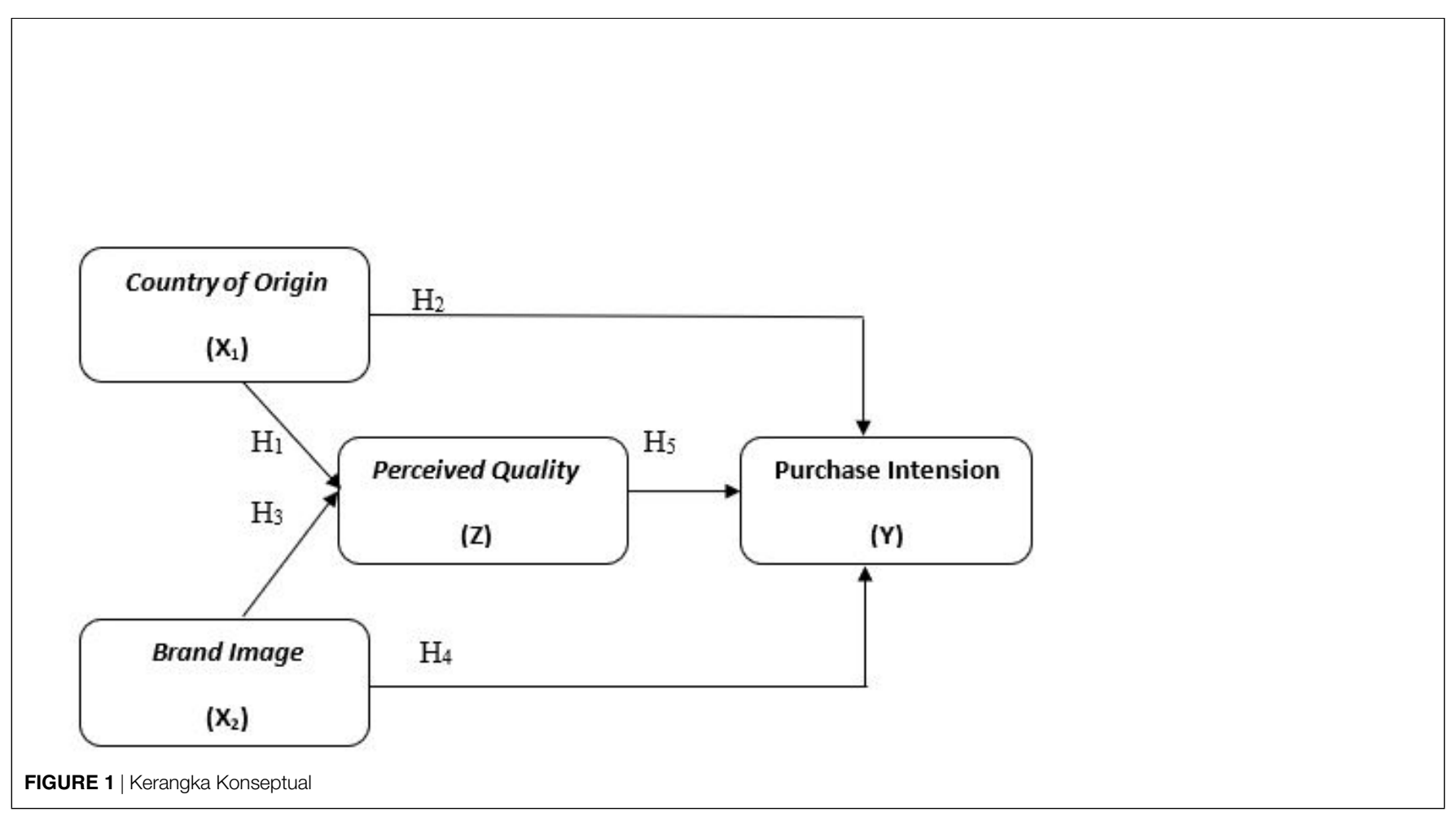




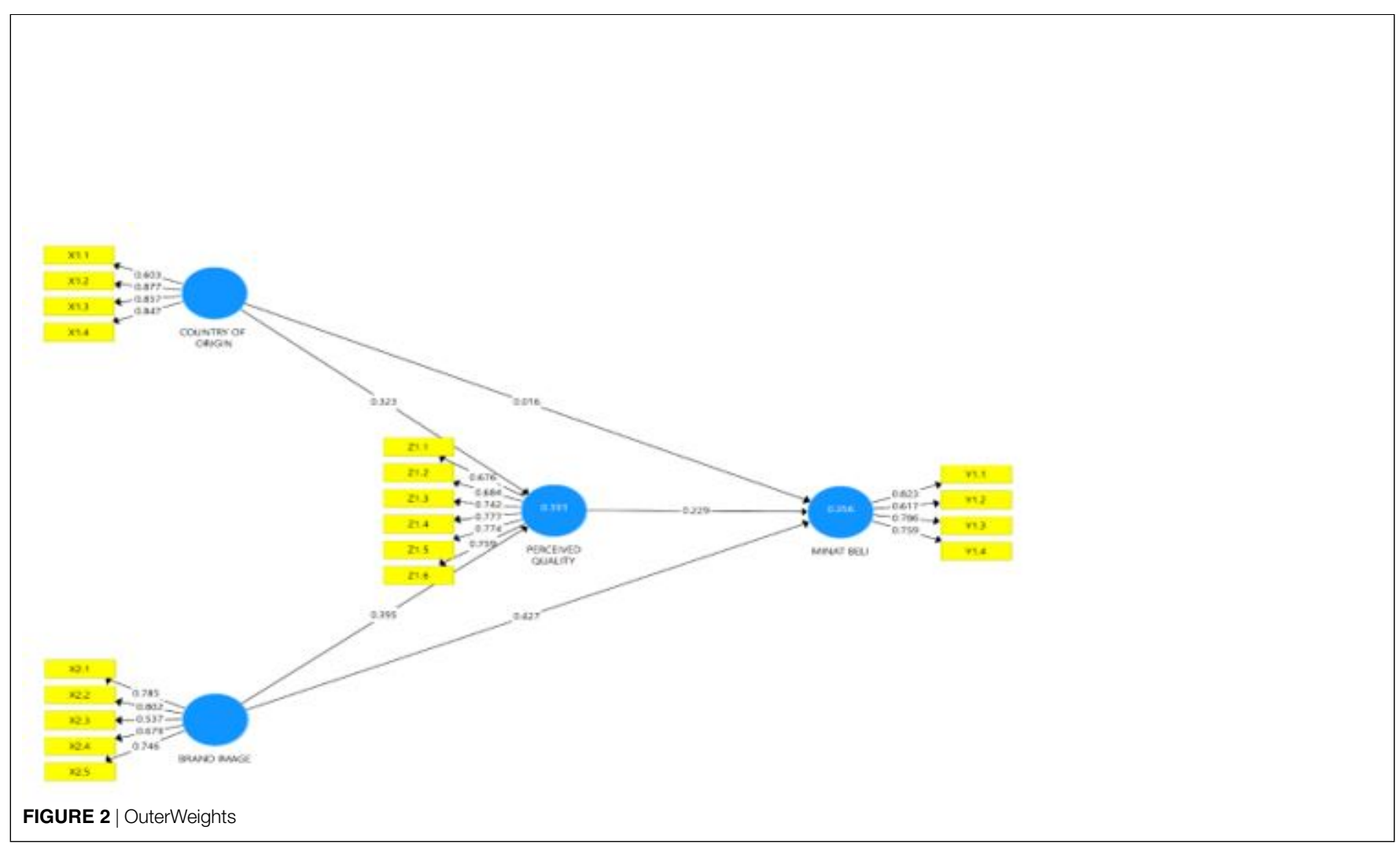




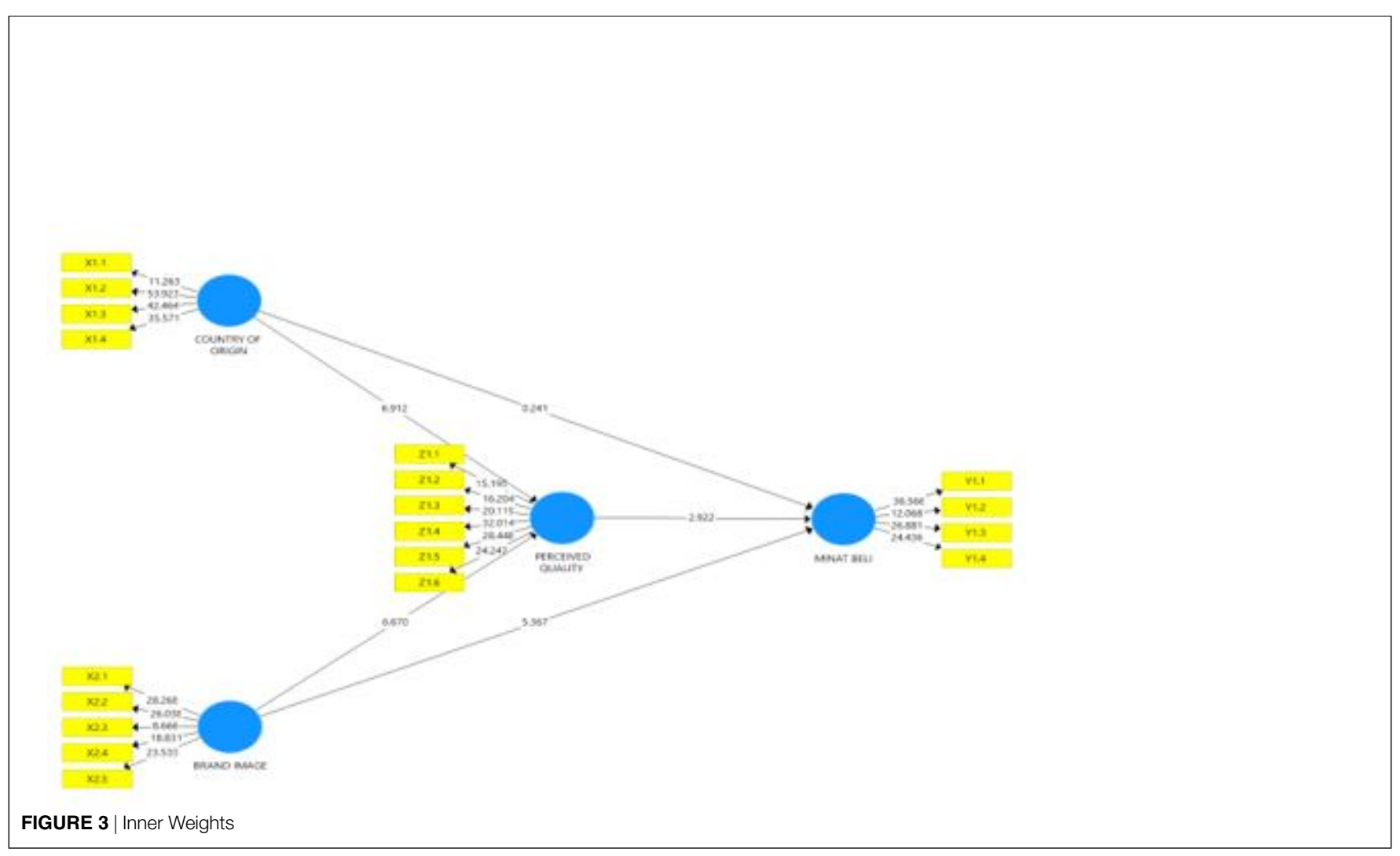




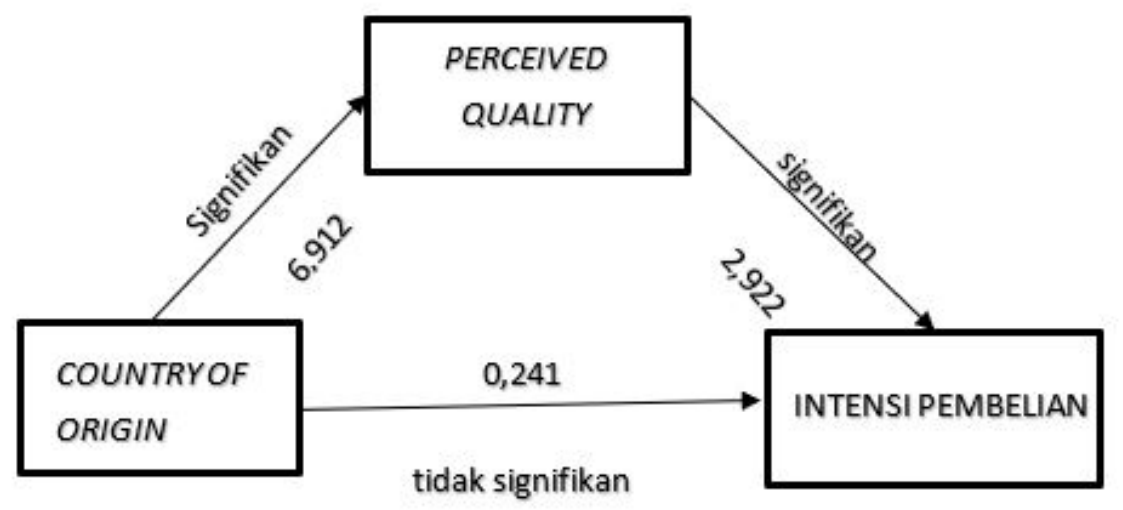

FIGURE 4 | Pengaruh Total Hubungan Countryof Origin terhadap Intensi pembelian dengan Perceived Quality sebagai variabel Intervening 


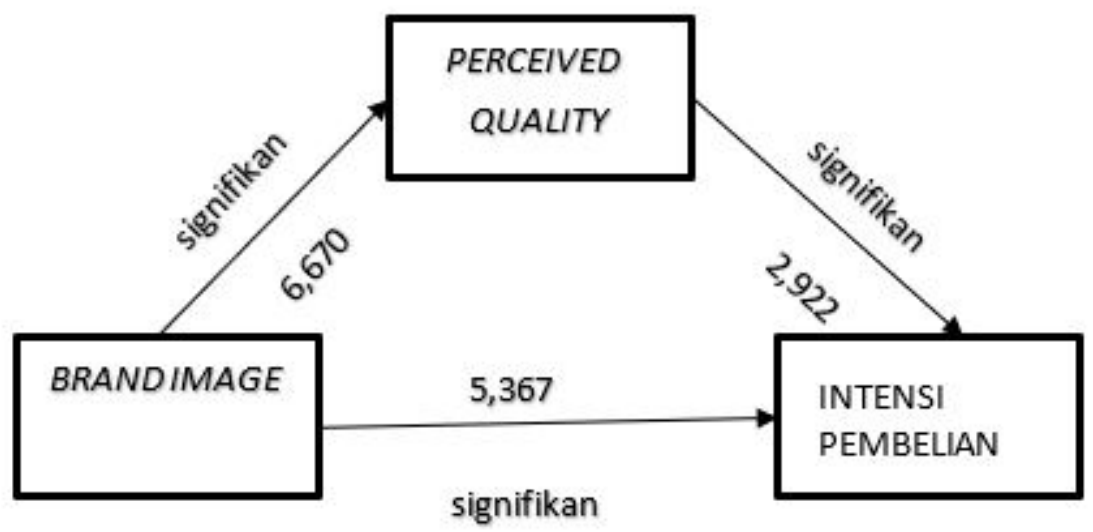

FIGURE 5 | Pengaruh Total Hubungan Brandlmage terhadap Intensipembelian dengan Perceived Qualitysebagai variabel Intervening 


\section{LIST OF TABLES}

1 Indonesia Skincare Sales Market Share 2018 . . . . . . . . . . . . . . . . . . . . . . . . . . . . . 35

2 Karakteristik Usia Responden . . . . . . . . . . . . . . . . . . . . . . . . . . . . . . . .

3 Karakteristik Merek Produk Skincare . . . . . . . . . . . . . . . . . . . . . . . . . . . . . . 37

$4 \quad$ Hasil Pengujian Pengaruh Langsung (Koefisien jalur) . . . . . . . . . . . . . . . . . . . . . . . . . . . 38

5 Hasil Pengujian Tidak Langsung (Indirect Effects) . . . . . . . . . . . . . . . . . . . . . . . . . . . . . 39

6 Pengaruh Total Hubungan antara Country of Origin dan Intensi pembelian dengan Perceived Quality sebagai Variabel Intervening . . . . . . . . . . . . . . . . . . . . . . . . . . . . . 40

7 Pengaruh Total Hubungan antara Brand Image dan Minat Beli dengan Perceived Quality sebagai Variabel Inter-

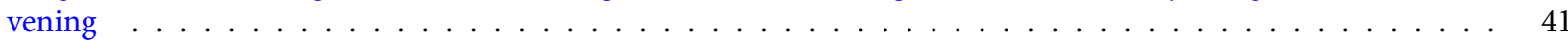


TABLE 1 | Indonesia Skincare Sales Market Share 2018

\begin{tabular}{lll}
\hline Indonesia Skincare Sales Market Share & $(\%)$ & Country of origin \\
SK II (PITERA) & $8.9 \%$ & Korea Selatan \\
LANEIGE & $7.7 \%$ & Korea Selatan \\
THE BODY SHOP & $5.5 \%$ & Brazil \\
INNISFREE & $4.6 \%$ & Korea Selatan \\
NATURE REPUBLIC & $4.2 \%$ & Korea Selatan \\
WARDAH & $4.1 \%$ & Indonesia \\
\hline
\end{tabular}

Sumber: Marketers.com 
TABLE 2 | Karakteristik Usia Responden

\begin{tabular}{lll}
\hline Usia & Jumlah Responden & Persentase (\%) \\
$19-23$ tahun & 157 & $52,33 \%$ \\
$24-27$ tahun & 143 & $47,67 \%$ \\
Jumlah & 300 & $100 \%$ \\
\hline
\end{tabular}

Sumber : Data primer diolah, 2020 
TABLE 3 | Karakteristik Merek Produk Skincare

\begin{tabular}{lll}
\hline Merek Produk & Jumlah Responden & Persentase (\%) \\
SK II & 26 & $8,7 \%$ \\
Laneige & 41 & $13,7 \%$ \\
Body Shop & 43 & $14,3 \%$ \\
Innisfree & 37 & $12,3 \%$ \\
Nature Republic & 63 & $21 \%$ \\
Wardah & 78 & $26 \%$ \\
Lainnya & 12 & $4 \%$ \\
Jumlah & 300 & $100 \%$ \\
\hline
\end{tabular}

Sumber: Data primer diolah, 2020 
TABLE 4 | Hasil Pengujian Pengaruh Langsung (Koefisien jalur)

\begin{tabular}{|c|c|c|c|c|c|c|}
\hline \multicolumn{7}{|c|}{ Koefisien jalurs } \\
\hline & Hipotesis & Arah & Besar Pengaruh & t Statistics (Ts) & t-tabel $(T t)$ & Keterangan \\
\hline COOàPQ & $\mathrm{H} 1$ & + & 0,323 & 6,912 & 1,967 & $\begin{array}{l}\text { Positif } \\
\text { Sig- } \\
\text { nifikan }\end{array}$ \\
\hline COOàMB & $\mathrm{H} 2$ & + & 0,016 & 0,241 & 1,967 & $\begin{array}{l}\text { Positif } \\
\text { Tidak } \\
\text { Sig- } \\
\text { nifikan }\end{array}$ \\
\hline BlàPQ & H3 & + & 0,395 & 6,670 & 1,967 & $\begin{array}{l}\text { Positif } \\
\text { Sig- } \\
\text { nifikan }\end{array}$ \\
\hline BlàMB & $\mathrm{H} 4$ & + & 0,427 & 5,367 & 1,967 & $\begin{array}{l}\text { Positif } \\
\text { Sig- } \\
\text { nifikan }\end{array}$ \\
\hline PQàMB & H5 & + & 0,229 & 2,922 & 1,967 & $\begin{array}{l}\text { Positif } \\
\text { Sig- } \\
\text { nifikan }\end{array}$ \\
\hline
\end{tabular}

Sumber: data primer diolah, 2020 
TABLE 5 | Hasil Pengujian Tidak Langsung (Indirect Effects)

\begin{tabular}{|c|c|c|c|c|}
\hline \multicolumn{5}{|l|}{ Indirect Effects } \\
\hline & Original Sample & $\begin{array}{l}t \quad T \\
\text { Stattabel } \\
\text { tics } \\
(T s)(T t)\end{array}$ & Hasil & Keterangan \\
\hline COOàPQà PI & 0,074 & $2,721,967$ & $\mathrm{Ts}>\mathrm{Tt}$ & $\begin{array}{l}\text { Positif } \\
\text { Sig- } \\
\text { nifikan }\end{array}$ \\
\hline BlàPQà PI & 0,091 & $2,55 \overline{6}, 967$ & $\mathrm{Ts}>\mathrm{Tt}$ & $\begin{array}{l}\text { Positif } \\
\text { Sig- } \\
\text { nifikan }\end{array}$ \\
\hline
\end{tabular}

Sumber: data primer diolah, 2020 
TABLE 6 | Pengaruh Total Hubungan antara Country of Origin dan Intensi pembelian dengan Perceived Quality sebagai Variabel Intervening

\begin{tabular}{lllll}
\hline Variabel & Besar Pengaruh & t statistics & $P$ values & Keterangan \\
COOàPQ & 0,427 & 6,912 & 0,000 & Signifikan \\
COOàMB & 0,395 & 0,241 & 0,810 & Tidak Signifikan \\
PQàMB & 0,229 & 2,922 & 0,004 & Signfikan \\
COOàPQàMB & 0,091 & 2,555 & 0,011 & Signifikan \\
\hline
\end{tabular}

Sumber: data primer diolah, 2020 
TABLE 7 | Pengaruh Total Hubungan antara Brand Image dan Minat Beli dengan Perceived Quality sebagai Variabel Intervening

\begin{tabular}{lllll} 
Variabel & Besar Pengaruh & t statistics & $P$ values & Keterangan \\
Bl à PQ & 0,016 & 6,670 & 0,000 & Signifikan \\
Blà PI & 0,323 & 5,367 & 0,000 & Signifikan \\
PQà PI & 0,229 & 2,922 & 0,004 & Signifikan \\
Bl à PQ à PI & 0,074 & 2,723 & 0,007 & Signifikan \\
\hline
\end{tabular}

Sumber: data primer diolah, 2020 